\title{
A MEDIAÇÃo NO ÂMBITO DA ECOLOGIA POLÍTICA ${ }^{1}$
}

\author{
Alejandro C. R. Werlang ${ }^{2}$ \\ Leticia Thomasi Jahnke ${ }^{3}$ \\ Mauro Gaglietti ${ }^{4}$
}

\begin{abstract}
Resumo
A ocorrência de um crime se dá quando há a subsunção de um determinado fato a um tipo legal que prevê uma conduta como delituosa. Ou seja, a análise de uma infração penal se dá estritamente em termos legais, não havendo uma perquirição de questões familiares e comunitárias, o que, na pós-modernidade, se torna necessário para efetiva resolução dos conflitos. Assim, o objetivo do presente texto é examinar os benefícios que a mediação pode trazer como efetiva forma de resolução de conflitos, o que pode ocorrer inclusive na esfera penal, buscando construir a ecologia dos vínculos, da ética, do direito, possibilitando a melhora da qualidade de vida, viabilizando-se um método no qual a aplicação coercitiva e terceirizada à Justiça Estatal cede lugar para um procedimento que tende à satisfação de desejos e à ampliação de responsabilidades entre as pessoas envolvidas em conflito.
\end{abstract}

Palavras-chave: Mediação. Resolução de conflitos. Direito Penal.

\section{INTRODUÇÃO}

\footnotetext{
${ }^{1}$ Esse texto surgiu de reflexões a partir do Curso sobre Mediação ministrado pelo Prof. Dr. Luis Alberto Warat em 1999 na UNICRUZ (Cruz Alta, RS) e com os Cafés Filosóficos de Porto Alegre, Passo Fundo e Santo Ângelo organizados pela IMED e o Mestrado em Direito da URI. Mais recentemente, o texto recebeu uma grande contribuição do Psicólogo Juan Carlos Vezzulla no curso ministrado acerca da Mediação em Passo Fundo em julho de 2011 junto ao Projeto Justiça Comunitária (Ver <http://justicacomunitariapf. blogspot.com> e, também, <http://maurogaglietti.imed.edu.br> ). Em razão da discussão sobre a necessidade de se ampliar a reflexão acerca dos métodos não adversariais de solução de conflito - justiça comunitária, mediação e práticas restaurativas - na disciplina Ecologia Política, ministrada por Mauro Gaglietti, no Mestrado em Direito na URI em Santo Ângelo (RS). A discussão contou com o aporte teórico buscado nos textos de Michel Foucault, Luiz Alberto Warat (jurista que atuou até 2010 no Mestrado em Direito da URI), Leonel Severo Rocha e João Martins Bertaso. O Projeto "Justiça Comunitária", aprovado pelo Ministério da Justiça está sendo implementado, desde julho de 2011, nos bairros Zachia e Valinhos, em Passo Fundo (disponível em: <http://justica comunitariapf. blogspot.com>).

${ }^{2}$ Juiz de Direito. Graduado em Direito pela Pontifícia Universidade Católica do Rio Grande do Sul. Especialista em Direito Processual: Grandes Transformações, pela Universidade do Sul de Santa Catarina -UNISUL. Mestrando em Direito pela Universidade Regional Integrada do Alto Uruguai - URI - Campus Santo Ângelo.

${ }^{3}$ Graduada em Direito pela Universidade Luterana do Brasil -ULBRA. Especialista em Processo Civil. Especialista em Direito Civil. Mestranda em Direito pela Universidade Regional Integrada do Alto Uruguai - URI. Membro do Grupo de pesquisa de Direito e Sociobiodiversidade, da Universidade Federal de Santa Maria - UFSM.

${ }^{4}$ Professor do Mestrado em Direito e do Curso de Graduação em Direito da URI (Santo Ângelo, RS); Doutor em História/PUCRS, Mestre em Ciência Política/UFRGS; Professor e Pesquisador da IMED (Passo Fundo, RS); Coordenador do Grupo de Pesquisa Justiça Comunitária na IMED e Professor Colaborador dos Cursos de Direito da FAI/UCEFF (SC) e da FEMA (Santa Rosa, RS). Junto a PUCRS, é, também, pesquisador associado ao grupo de estudos e pesquisa ética e direitos humanos registrado no diretório do CNPq, sendo coordenado pela Profa. Dra. Beatriz Gershenson Aguinsky. Coordena o Curso de Especialização (Pós-Graduação) em Mediação de Conflitos e Justiça Restaurativa na IMED (Passo Fundo, Porto Alegre, Santo Ângelo). E-mail: maurogaglietti@bol.com.br .
} 
A partir de Kant e as suas condições de razão, Luis Alberto Warat (2004, p.33 e ss.) há muito já expressava que fora de qualquer atitude holística, de um direito encarregado de suprimir os conflitos na sociedade, tudo é um absurdo. Talvez esse seja o modo de se tentar aproximar a cultura do Direito a uma ética comprometida com a qualidade de vida à medida que se avança rumo ao fomento de uma cultura jurídica não adversarial.

Os conflitos mediados podem servir de auxílio humano para a afirmação recíproca dos movimentos próprios daqueles que vivem e provam o conflito em suas vidas, transformando suas conflitualidades vinculares em movimento próprios de empoderamento a partir da crença de que são capazes de criar os problemas e tentar buscar um tratamento ao conflito, sobretudo daqueles que têm vínculos afetivos e há anos se conhecem e vivem juntos, buscando construir a ecologia dos vínculos, da ética, do direito, possibilitando a melhora da qualidade de vida.

Assim, o objetivo é examinar as possíveis relações entre a mediação de conflitos e a ecologia política. Trata-se de estudar a proposta jurídica de resolução de conflitos que vai além do normativismo. A mediação é uma estratégia política exitosa em termos educativos, como realização de cidadania, dos direitos humanos e da democracia. Tecendo como parâmetro a mediação como um método não adversarial de resolução de conflitos, pode-se circunscrevê-la nos tipos de procedimentos que, contemporaneamente, tendem a conduzir para uma radical modificação no sistema de soluções ou de transformações de controvérsias e, de modo muito singular, problemas e questões de natureza jurídica.

A mediação penal, por exemplo, pode estar inserida no que se convencionou chamar de "acesso à justiça" no âmbito da justiça criminal. Tendo como objetivo tratar tal temática, percorrem-se alguns aspectos que caracterizam a história da teoria do crime e da penalidade, buscando-se as bases epistemológicas da Justiça Comunitária e da Justiça Estatal. Tal percurso associa-se à investigação de fatores contemporâneos que retroalimentam os diferentes paradigmas da justiça retributiva e da justiça restaurativa.

Assim, dá-se destaque à questão da produção de singularidades, para se pensar em que medida as práticas e discursos existentes no âmbito das relações humanas 
produzem o modo de ser dos sujeitos, e como os modos de busca da solução de conflito evidenciam, ou não, uma forma, previamente, determinada.

\section{Mediação sob a perspectiva da reconstrução}

A mediação como uma forma ecológica viabiliza um acordo transformador das diferenças, como assegura Warat. A natureza política da mediação é representada pela estruturação da visão ecológica do mundo - um componente estrutural do paradigma político e jurídico da transmodernidade - à medida que se considera as práticas sociais da mediação como as principais responsáveis por uma certa configuração de autonomia, democracia e cidadania, na medida em que educam, facilitam e auxiliam a produzir diferenças e a realizar tomadas de decisões sem a intervenção de funcionários do Estado que decidem no lugar dos afetados por um conflito.

Ainda, o sentido político da mediação associa-se, direta e indiretamente, à ampliação da capacidade das pessoas para se autodeterminarem em relação e com os outros - autonomia na produção da diferença, ou seja, na produção do tempo com o outro. Warat (1998, p.55) assinala, com relação a tais aspectos:

\footnotetext{
Um trabalho de reconstrução simbólica dos processos conflitivos das diferenças que nos permite formar identidades culturais - de nos integrar no conflito com o outro -, com um sentimento de pertinência comum. Uma forma de poder perceber a responsabilidade que toca a cada um num conflito, gerando devir (devires) reparadores e transformadores.
}

Assim, a mediação é uma forma ecológica de resolução dos conflitos jurídicos, policiais, familiares, de vizinhança, institucionais e comunitários, buscando, sobretudo, uma melhor qualidade de vida das partes envolvidas em controvérsias. Viabiliza-se um método no qual a aplicação coercitiva e terceirizada à Justiça Estatal - ajustar o acordo às disposições do Direito positivo - cede lugar para um procedimento que tende à satisfação de desejos e à ampliação de responsabilidades entre as pessoas envolvidas em conflito.

Percebe-se, desse modo, que, na mediação, a autocomposição é ecológica por duas fortes razões. Em primeiro lugar, ela pode ser considerada como uma forma de realização da autonomia, na medida em que educa, facilita e ajuda à produção das diferenças na produção do tempo com o outro, ao modificar as divergências. Isso quer dizer que o amor e o ódio são formas de convivência com a conflitividade, com a incompletude que a conflitividade existencial determina. Em segundo, a mediação pode 
ser considerada uma forma ecológica de autocomposição porque, ao procurar um acordo transformador de diferenças, facilita uma considerável melhoria na qualidade de vida de um casal, de vizinhos, de colegas de aula, de colegas de trabalho, de amigos.

Diferente dessa direção de acesso à justiça, percebe-se outra possibilidade, a mais utilizada comumente, que se refere à sentença judicial. Assinala-se que, quando se decide judicialmente, se consideram normativamente os efeitos. Desse modo, o conflito pode ficar em estado latente, retornando agravado em qualquer momento futuro.

Assim, examina-se a mediação como referência a uma solução jurídica dos conflitos que atende a uma satisfação de todas as partes e que está baseada em uma proposta autorregulada por elas mesmas, com o apoio de um mediador, que colabora na escuta, na interpretação e na transformação.

Em outras palavras, é um sistema do ganha/ganha no qual ninguém sai perdendo, na medida em que as partes envoltas no conflito decidem a melhor maneira de resolver o problema criado por elas. Isso só ocorre em virtude do processo de mediação ser assistido pelo mediador - um terceiro que está alheio ao conflito e que não pode propor soluções, atuando com a concordância das pessoas afetadas pelo conflito, com o propósito de facilitar a aproximação e a comunicação das partes.

Isso quer dizer que a mediação é o espaço mais apropriado para as pessoas realizarem um processo psíquico de reconstrução simbólica. Quando se resolve um conflito é porque as partes envolvidas puderam reconstruí-lo simbolicamente, na medida em que conseguiram transformá-lo por tê-lo interpretado, reconstruindo-o.

Quer-se aqui tratar acerca do acesso à justiça no âmbito da justiça criminal. Para tanto, percorrem-se alguns aspectos que caracterizam a história da teoria do crime e da penalidade, buscando-se as bases epistemológicas da Justiça Comunitária e da Justiça Estatal. Tal percurso associa-se à investigação de fatores contemporâneos que retroalimentam os diferentes paradigmas da justiça retributiva e da justiça restaurativa. Assim, dá-se destaque à questão da produção de singularidades, para se pensar em que medida as práticas e discursos existentes no âmbito das relações humanas produzem o modo de ser dos sujeitos, e como os modos de busca da solução de conflito evidenciam, ou não, uma forma, previamente, determinada. Seguindo a inspiração de Deleuze e Guattari (1997, p.80), propomos um “aprender a desfazer, e a desfazer-se”, que, segundo eles, é próprio da máquina de guerra, o não fazer do guerreiro, desfazer o 
sujeito. Desse modo, percebe-se a existência de um espaço "estriado do Estado" que se caracteriza pela repetição, do eterno retorno ao mesmo, por intermédio dos jogos de poder instituídos. O espaço liso fora do Estado é o da produção da diferença. Lança-se, desse modo, um questionamento com a seguinte formulação: quem sabe a Justiça Restaurativa possa propor outro olhar sobre a questão da resolução de conflitos?

\section{A cultura do controle}

Em nossa sociedade, a justiça é concebida, muitas vezes, como aplicação da lei. Por decorrência, o crime é definido pela violação ou infração de uma lei. Nessa perspectiva, o que define a ofensa e aciona o processo criminal é alguém que cometeu um ato definido em lei como crime - e não a natureza do dano ou do conflito em si mesmos.

A ênfase no ato de violar a norma de direito penal é o que permite que tanto ofensa como culpa sejam definidas em termos estritamente legais. Assinala-se que as questões familiares e comunitárias (éticas e sociais) se tornam secundárias e, em alguns casos, até irrelevantes. Desse modo, o contexto do ato é desconsiderado, exceto na medida de suas implicações legais. Os agentes estatais chamam para si a responsabilidade de conduzir o processo, e tudo isso a sociedade aceita como bastante natural e inevitável.

A nova física da dor, utilizada nos séculos XVIII e XIX, foi sendo administrada às portas fechadas nas prisões pelo Estado, de modo que a pena de privação de liberdade é que permitia graduar o tempo de punição segundo a gravidade da ofensa. Depreende-se disso que as prisões constituíam um meio de dosar a punição em unidades de tempo, oferecendo uma aparência de racionalidade e mesmo de ciência à aplicação da dor.

No início da Idade Moderna, as formas de punição visavam, sobremaneira, ao corpo, muitas vezes fazendo uso de tecnologias que causavam intenso sofrimento físico e psíquico aos encarcerados. Portanto a utilização moderna da prisão buscava atingir, principalmente, a alma.

À justiça se atribui a função de não mais punir as infrações dos indivíduos, mas de corrigir suas virtualidades. Para tanto o judiciário precisou interligar várias 


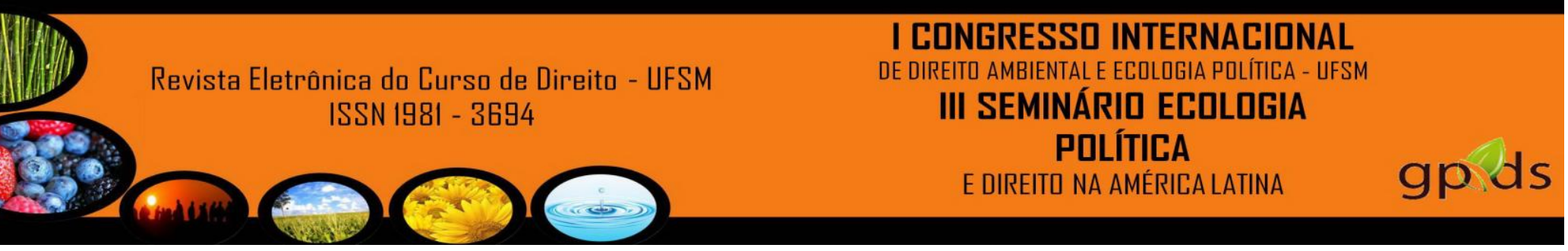

instituições em teia, instituições essas que não estão abrigadas por tal poder, para desempenhar a função do próprio judiciário.

Com a consolidação do pensamento de que a penalogia assume nítidas funções de controle, especialmente à prevenção de delitos, não tanto direcionada ao passado, mas, sim, ao futuro, pode-se referir que o marco atual oferece uma representação social expansivo-expressiva da biopolítica do Direito Penal, que é consensual, convertendo-se, por isso, em uma "rara unanimidade". Vive-se numa sociedade do controle, na qual se tem intensificado, como nunca, o recurso ao Direito Penal para combater a criminalidade, que se intensifica. Há, efetivamente, uma guerra santa que justifica políticas criminais de segurança coletiva, culminando no fato de que lei e ordem e tolerância zero (versões pós-modernas do teste de "fidelidade ao Direito") se transformam em bens jurídicos.

De outras, é sabido que o fenômeno expansivo não é monocausal, tampouco decorre da produção legislativa de um Estado totalitário; ao contrário, o movimento expansivo é produto de diversas orientações e saberes que acabam convergindo no denominador comum que deságua em uma verdadeira proposta securitária, que, como refere Silva Sánchez, se integrou nesse novo consenso social sobre o papel do Direito Penal. Assim, as premissas ideológicas (Direito Penal simbólico) e os movimentos totalizantes de "lei e ordem" não desapareceram do cenário social; ao contrário, passaram a se acomodar, "comodamente", nesse novo consenso (SILVA SÁNCHEZ, 2002, p.15-90).

Dito de outro modo, a expansão do Direito Penal, que é característica marcante das sociedades pós-modernas, está relacionada com "causas mais profundas", na precisa observação de Silva Sánchez, para quem a expansão deita suas raízes no modelo social, notadamente a partir de novas expectativas que as camadas sociais têm em relação ao papel conferido ao Direito Penal. Isso culmina, no âmbito cultural, na formação de uma verdadeira demanda social por mais proteção e segurança frente aos novos riscos (GARLAND, 2008, p.41).

Dessarte, o ponto de partida real para a análise do tema pouco tem a ver com os movimentos de Law and order, que davam respaldo às políticas criminais totalizantes da década de 70. A pedra de toque é a crescente demanda social por proteção e segurança, facilmente detectada na sociedade moderna, que vive sob os influxos sociológicos da sociedade do risco (BUSTOS RAMÍREZ e HORMAZÁBEL MALARÉE, 2006, p.22).

Nesse passo, Silva Sánchez, dissertando sobre as causas da "crise de crescimento" (SILVA SÁNCHEZ, 2002, p.09) do Direito Penal nas sociedades pós-industriais, confere destaque à questão da aparição de novos interesses ou bens jurídicos, especialmente aos bens atualmente escassos, como o meio ambiente ou bens coletivos ou difusos, relacionando-os ao aparecimento de novos riscos e à institucionalização da insegurança, que, de resto, não deixam de ser produtos da sociedade do risco. Também, aponta o surgimento de uma sociedade de sujeitos passivos, dependentes do Estado de bem-estar, que valorizam, de forma essencial, a questão da segurança, o que implica a redução do risco permitido na sociedade, havendo, inclusive, uma identificação maior com as vítimas. Esse fato reforça o consenso punitivo, que, por fim, descansa no descrédito de outras instâncias de proteção, preponderando a resposta penal. A própria globalização, que intensificou o 


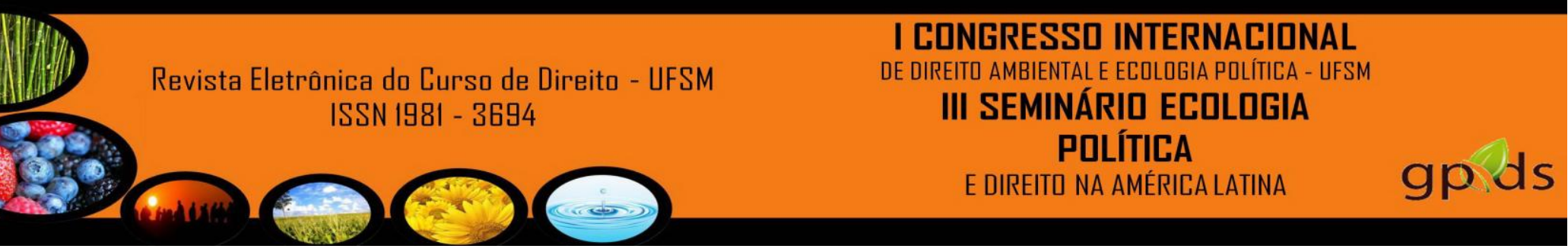

intercâmbio de pessoas e o comércio transfronteiriço, dando azo a crimes transnacionais (tráfico de drogas, armas e pessoas, crimes ambientais, terrorismo, crime organizado etc), por sua sorte, também fomentou a expansão do controle penal rumo a um Direito Penal internacional.

Em suma, pode-se referir que a aventura securitária é produto da pósmodernidade ou da modernidade tardia, que, no ambiente de relações sociais, econômicas e culturais, trouxe consigo um conjunto de riscos, complexidade e insegurança (CALLEGARI e WERMUTH, 2010, p.13), bem como problemas do controle social, que afetaram, sobremaneira, o Direito Penal (FUENTES, 2008, p.41), que, agora, não mais discute os efeitos da sanção penal, mas se vê envolto na missão de dispor de novas formas de prevenção e minimização dos riscos, os quais, no cenário da pós-modernidade, não param de crescer (BRANDARIZ GARCÍA, 2004, p.15 e ss).

No limite, os anos 80/90 informam o surgimento de uma nova política criminal, que tem suas raízes numa nova experiência do crime e da insegurança objetiva e subjetiva, estruturada pelos arranjos sociais, econômicos e culturais singulares da pósmodernidade (GARLANT, 2008, p.181), que pode ser entendida como a aproximação do mundo industrializado, com o emprego da força material e a maquinaria da produção (JAMESON, 2004, p. 22). E tal sinal da pós-modernidade forjou um mundo em disparada (ou em descontrole), promovendo um "desencaixe" das instituições sociais (GIDDENS, 2003, p.18), constituindo, ainda, conforme entendimento de Habermas, um projeto inacabado, polêmico e multifacetado, que se apresenta com o desenvolvimento das sociedades modernas, que, de resto, veem-se envoltas com a complexidade e o risco (1990, p.11).

A modo de sintetizar, a pós-modernidade ou modernidade tardia ${ }^{5}$, novo padrão distintivo de relações econômicas e sociais, trouxe, no seu bojo, um conjunto de riscos, inseguranças e problemas de controle social, reconfigurando, dessa forma, as expectativas sociais com relação às políticas criminais de repressão à criminalidade, já que o caldo cultural pede o endurecimento da resposta penal (MENDOZA BUERGO, 2003, p. 67).

Dizendo de outra maneira, o endurecimento da resposta penal decorre de profundas mudanças vivenciadas pela sociedade moderna, uma vez que é do lugar comum na literatura sociopolítica que está constituída pela caracterização como uma sociedade do risco (LUHMANN, 2006, p. 57). E, com isso, se quer designar como um conjunto de fenômenos produzidos no desenvolvimento da sociedade industrial, cujo denominador comum é o debilitamento de certas instituições tradicionais, o que gerou uma sensação intensa de insegurança nas pessoas.

Com efeito, a sociedade contemporânea sofre com a constante mudança e aceleração, provocada sobremaneira pela economia globalizada de consumo e de comunicação de massas, suscitando um insuperável paradoxo entre maior

Ver BAUMAN, Zygmunt. O mal-estar da pós-modernidade. Tradução de Mauro Gama e de Cláudia Martinelli Gama. Rio de Janeiro: Jorge Zahar, 1998. 
flexibilidade/liberdade e, em contrapartida, uma vulnerabilidade maior (precariedade/instabilidade/incerteza (DE GIORGI, 2006, p.129). De efeito, nesse ambiente de sensação (subjetiva) de insegurança (BAUMAN, 2007, p. 11), a questão da segurança se apodera do discurso público, crescendo a ansiedade face à marginalidade que o processo tecnológico causa.

Daí o acerto da teoria social de Garlant quando assevera que a mutação do Leviatã penal, ou "aventura securitária" das sociedades pós-industriais do século XXI, somente pode ser compreendida nos contornos da sociologia do risco. De se notar, conforme Prittwitz, que o teorema da sociedade do risco, com as graves mutações que produziu na genética do controle penal, foi o que preparou o terreno para a edificação do Direito Penal de exceção (Direito Penal do inimigo) ou a "Revolução Policial"(PALIDDA, 2008, p. 41)/’'Direito de Luta" (DONINI, 2008, p.29) no âmbito do Direito Penal da sociedade do risco.

Todavia, a excepcionalidade/emergência penal cumpre um distanciamento em relação aos sentimentos de ódio recíproco entre o "eu" e o "outro", geradores de ressentimentos, interrogando a globalidade da violência que irrompe no mundo, principalmente após os atentados de 11.09.2001, que trouxeram reflexos à economia do controle penal, que restou aparelhado em termos bélicos, consolidando o paradigma da guerra.

Sob esse aspecto, é necessário que se adote um pensamento complexo para poder compreender o tema da violência mundial ( e a insegurança que desemboca no sistema penal), o que passa, sem dúvida, pela contestação e destruição do modelo da globalização econômica (BAUDRILLARD e MORIN, 2004, p.63). Ora, conforme Baudrillard e Morin, o planeta vive um "estado de crise", na medida em que o mercado da concorrência (guiado pelo liberalismo, em que todos entram no circuito das mercadorias), invadiu inclusive setores humanos, provocando decadência e degradação (2004, 61).

Nesse contexto de crise e decadência é preciso tornar o "planeta um bem socializável, que é preciso acabar com as guerras e resolver as desigualdades mais graves" (BAUDRILLARD e MORIN, 2004, p.77). Em síntese, para uma compreensão e superação do pensamento totalizante da repressão como a única resposta para o enfrentamento da 
insegurança e criminalidade, apresenta-se como necessária uma "religação dos saberes" ou adoção de um pensamento sistêmicos que de conta da complexidade do tema ${ }^{6}$.

Com efeito, não se pode perder de vista que o mundo atual está atravessado por sistemas complexos (economia, política, religião, sociedade, cultura etc.), que não resistem a uma abordagem puramente analítica (como quer o sistema penal), já que, ignorando-os no equacionamento da criminalidade/insegurança, se ignoram as denominadas "propriedades emergentes".

Em uma palavra, a insegurança e o risco não podem ser dissociadas do sistema econômico e do sistema social, que se agudizaram na pós-modernidade, culminando em levar o homem a uma condição inumana. Ora, priorizar somente a resposta penal, descurando das "propriedades emergentes" (pobreza, vulnerabilidade, excedência humana etc) somente intensifica o processo de dor, sofrimento humano rumo a exclusão ${ }^{7}$. Como diz Morin, é preciso "civilizar a terra", mesmo sabendo que a civilização não pode existir sem um mínimo de barbárie, bem como fraternizar a humanidade, o que passa pelo reconhecimento e compreensão do "outro" ( MORIN, 2011, p.212), mesmo que criminoso e/ou desviante.

\section{CONSIDERAÇÕES FINAIS}

Pelo exposto, busca-se incorporar as abordagens dialógicas ao Poder Judiciário, sobretudo, àquelas associadas à ação pedagógica desses meios de solução pacífica de controvérsias. Até mesmo a conciliação deve ser conduzida por uma equipe multidisciplinar independente da atuação judicial. Será fundamental, no entanto, que os juízes tenham a compreensão de que o julgamento é o mais poderoso e, ao mesmo tempo, o mais precário modo de solucionar uma controvérsia. Na verdade a sentença do magistrado, como regra, não resolve o conflito, apenas enseja o término de um processo, sendo que uma das partes - por ficar contrariada - retornará, provavelmente, com um novo processo, ao judiciário.

É com esta visão que devem ser debatidos e aperfeiçoados tanto o projeto de lei da mediação, que visa a suplementar o processo civil com várias alternativas e

\footnotetext{
6 Ver MORIN, Edgar. A religação dos saberes: o desafio do século XXI. Tradução de Fávia Nascimento. 3. ed. Rio de Janeiro: Bertrand Brasil, 2002, p. 489-499. Para Morin, o conhecimento é uma "tradução" que estimula a reflexão, que, no seu entendimento, é o "que mais faz falta" na atualidade.

Consultar MAFFESOLI, Michel. A violência totalitária: ensaio de antropologia política. Porto Alegre: Sulina, 2001, p. 242-251.
} 
oportunidades de encontro dialógico, quanto o projeto de lei da mediação penal e outras práticas restaurativas, voltado à adoção de núcleos de justiça restaurativa, num alargamento do processo penal, relativamente às infrações de pequeno ou médio potencial ofensivo; ambos em tramitação no Congresso Nacional.

Por fim, salienta-se que é verdade que é na ciência que estão os princípios, os critérios técnicos, mas também é lícito afirmar que é no sentimento do mundo, na troca de olhares, no reconhecimento e no perdão, enfim, no amor, que se faz a humanidade e a ciência da humanidade. Como assinalou Luis Alberto Warat ao longo de sua obra, tanto para mediar, como para viver, é preciso sentir o sentimento. O mediador não pode se preocupar por intervir no conflito, transformá-lo. Ele tem que intervir sobre os sentimentos das pessoas, ajudá-las a sentir seus sentimentos, renunciando a interpretação e aos julgamentos.

Os conflitos nunca desaparecem, se transformam; isso porque, geralmente, tentamos intervir sobre o conflito e não sobre o sentimento das pessoas. Por isso, é recomendável, na presença de um conflito pessoal, intervir sobre si mesmo, transformar-se internamente, então, o conflito se dissolverá (se todas as partes comprometidas fizerem a mesma coisa). O mediador deve entender a diferença entre intervir no conflito e nos sentimentos das partes, fazendo com que olhem a si mesmas e não ao conflito, como se ele fosse alguma coisa absolutamente exterior a elas mesmas. Quando as pessoas interpretam (interpretar é redefinir), escondem-se ou tentam dominar (ou ambas as coisas).

Quando as pessoas sentem sem interpretar, crescem. Os sentimentos sentem-se em silêncio, nos corpos vazios de pensamentos. As pessoas, em geral, fogem do silêncio. Escondem-se no escândalo das palavras. Teatralizam os sentimentos, para não senti-los. O sentimento sentido é sempre aristocrático, precisa da elegância do silêncio. As coisas simples e vitais como o amor entende-se pelo silêncio que as expressam. A energia que está sendo dirigida ao ciúme, à raiva, à dor tem que se tornar silêncio. A pessoa, quando fica silenciosa, serena, atinge a paz interior, a não violência, a amorosidade. Estamos a caminho de tornarmo-nos liberdade. Essa é, segundo Warat, a meta mediação. 


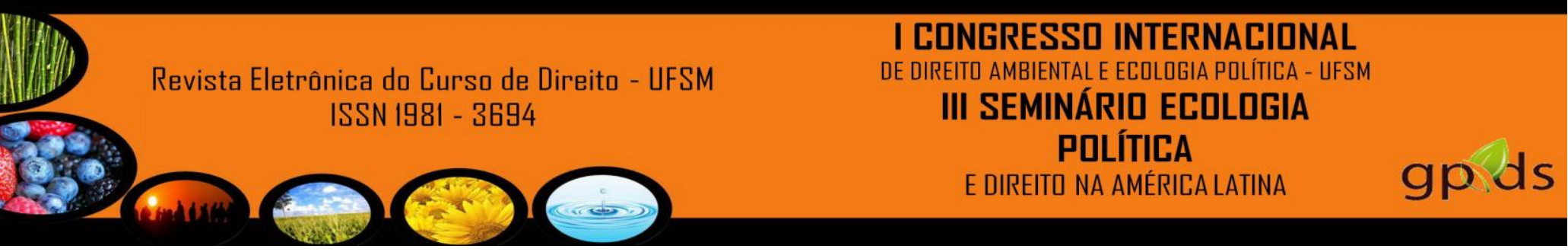

Assim, a mediação é uma forma ecológica de resolução dos conflitos jurídicos, policiais, familiares, de vizinhança, institucionais e comunitários, buscando, sobretudo, uma melhor qualidade de vida das partes envolvidas em controvérsias. Viabiliza-se, nesses termos um método no qual a aplicação coercitiva e terceirizada à Justiça Estatal - ajustar o acordo às disposições do Direito positivo - cede lugar para um procedimento que tende à satisfação de desejos e à ampliação de responsabilidades entre as pessoas envolvidas em conflito.

\section{REFERÊNCIAS BIBLIOGRÁFICAS}

BAUDRILLARD, Jean; MORIN, Edgar. A violência no mundo. Tradução de Leneide Duarte-Plon. Rio de Janeiro: Anima, 2004

BAUMAN, Zygmunt. Tempos Líquidos. Tradução de Carlos Alberto Medeiros. Rio de Janeiro: Jorge Zahar, 2007.

BRASIL. Constituição Federal. Disponível em: < . Acesso em 02 set. 2012.

BRANDARIZ GARCÍA, José Ángel. Itinerários de evolución del sistema penal como mecanismo de control social en las sociedades contemporáneas. In: FARALDO CABANA, Patricia (Dir.); BRANDARIZ GARCÍA, José Ángel e Hermán Bouvier. Madrid: Traficantes de sueños, 2006.

BUERGO, Blanca. Gestion del riesgo y política criminal de seguridad em la sociedad del riesgo. In: AGRA, Cnadido da; LUIS DOMÍNGUEZ, José; GARCÍA AMADO, Juan Antonio, HEBBERECHT, Patrick; RECASENS, Amadeu. La seguridad em la sociedad del riesgo: un debate abierto. Barcelona: Atelier, 2003.

BUSTOS RAMÍREZ, Juan J; HORMAZÁBEL MALARÉE, Hernán. Lecciones de derecho penal: parte general. Madrid: Trotta, 2006.

CALLEGARI, André Luís; WERMUTH, Maiquel Ângelo Dezordi. Sistema penal e política criminal. Porto Alegre: Livraria do Advogado, 2010.

DE GIORGI, Raffaele. Direito, tempo e memória. Tradução de Guilherme Leite Gonçalves. São Paulo: Quartier Latin, 2006.

DONINI, Massimo. Derecho penal de lucha: lo que el debate sobre el derecho penal del enemigo no deve limitarse a exorcizar. Tradução de Pablo Guérez Tricarico. In: CANIO MELIÁ, Manuel; POZUELO PÉREZ, Laura. Política criminal em vanguardia: inmigración clandestina, terrorismo, criminalidad organizada. Navarra: Thomson Civitas, 2008.

FUENTES, Francisco Maldonado. Derecho penal excepcional y delincuencia. Reflexiones sobre la extensión y alcances de los nuevos modelos de legislación penal. In: COLlAO, Luis Rodríguez (Org.) Delito, pena y proceso: livro homenaje a la memoria del profesor Tito Solari Peralta. Santiago de Chile: Editorial Jurídica de Chile, 2008.

GARLANT, David. A cultura do controle: crime e ordem social na sociedade contemporânea. Tradução de André Nascimento. Rio de Janeiro: Revan, 2008.

GIDDENS, Anthony. Mundo em descontrole: o que a globalização está fazendo de nós. Tradução de Maria Luiza X de A. Borges. 3. ed. Rio de Janeiro: Record, 2003. 
